\title{
Strengthening participation by young women sex workers in HIV programs: reflections on a study from Bangkok, Thailand
}

This article was published in the following Dove Press journal:

International Journal of Women's Health

5 September 2017

Number of times this article has been viewed

\author{
Cath Conn \\ Kristel Modderman \\ Shoba Nayar \\ School of Public Health and \\ Psychosocial Studies, Auckland \\ University of Technology, Auckland, \\ New Zealand
}

Background: Participation is an accepted means of increasing the effectiveness of public health programs, and as such, it is considered an important component of HIV interventions targeting at-risk youth. The situation of young women sex workers in Thailand is alarming on many fronts, including that of HIV risk. As a result, HIV programs in Thailand are the key interventions undertaken in relation to young women sex workers' health. A small-scale study used semistructured interviews to explore the participation reports of five young women sex workers, as well as the related views of two community support workers, who lived and worked in Bangkok, Thailand.

Discussion: This study is considered in the light of current research on - as well as new opportunities and challenges offered for - participation by vulnerable groups in the context of digital society. Thematic analysis of the interview data identified barriers to participation, including the illegality of sex work, fear, and lack of trust of the authorities, as well as widespread social stigma. Such barriers resulted in young women seeking anonymity. Yet, promisingly, young women positioned themselves as experts; they are involved in peer education and are supportive of greater involvement in HIV programs, such as further educational initiatives and collective actions.

Conclusion: There is a need for a more empowerment-oriented participation practice positioning young women sex workers as expert educators and codecision makers within a model of participation that is also accountable, such as including young women as members of program boards. Beyond current norms, there are new opportunities emerging because of the increasing availability of smartphone/Internet technology. These can support activist and codesign participation by young women sex workers in HIV programs. However, any developments in participation must maximize opportunities carefully, taking into consideration the difficult social environment faced by young women sex workers as well as the need for strategies to address illegality and stigma.

Keywords: community participation, prosumer, epublic health, peer educator, stigma

\section{Background}

Participation in public health programs is linked to longstanding notions of citizens' involvement in decision-making and a well-established recognition of the role of community in primary health care and public health initiatives. ${ }^{1,2}$ Participation by communities in health programs has been shown to increase effectiveness as program decision makers are better informed by those using and needing interventions; moreover, there is increased "buy-in" from users and hence better utilization as a result. ${ }^{3}$ In addition, for institutions aiming to practice good governance, accountability to communities
Correspondence: Cath Conn School of Public Health and Psychosocial Studies, Auckland University of Technology (AUT), AUT South Campus, 640 Great South Road, Manukau, Auckland, New Zealand

Tel +6499219999

Email cath.conn@aut.ac.nz 
serves as a key tenet and, as such, requires statutory demonstrations of community participation. ${ }^{4}$ However, while theory underpinning participation is often enshrined in program documents, the social reality of many health programs is that pressures of top-down decision-making create resistance to effective participation. ${ }^{5}$ Furthermore, participation theory often assumes homogeneity and agreement within communities; yet, this is often not the case for marginalized groups who are stigmatized and excluded. ${ }^{6}$

Young women sex workers invariably face multiple vulnerabilities because of their age and because of other harmful determinants in their work and lives. ${ }^{7}$ In Thailand, many women enter sex work at a young age; they are subject to multiple vulnerabilities, including poverty, low levels of education, and gender inequality. In addition, in relation to their occupation and HIV risk, they face dangers because of the illegality of sex; many young women are the subject of trafficking for sex work; migrant and rural women are at further risk from sex work; and violence, stigma, drug use, and unsafe workplaces are common experiences..$^{8-11}$

In the face of these challenges, there is widespread agreement that sex workers' participation is vital in addressing HIV among this most-at-risk group. In 2012, the World Health Organization stated that

the most successful interventions with sex workers have combined multiple components - implemented with strong community involvement and backed by supportive policies - to maximize positive outcomes. ${ }^{12}$

Further, the UNAIDS Guidance Note on HIV and Sex Work emphasizes that HIV-related services should always be designed with the full participation of the affected community, namely, sex workers. ${ }^{13}$

The Thai government has been committed to tackling HIV among sex workers through appropriate programming since the 1980s; the first case of HIV in Thailand was reported in $1984 .{ }^{14}$ Notably, in 1989, a national campaign for $100 \%$ condom use was implemented, which had a significant impact on reducing HIV prevalence among sex workers. ${ }^{15-17}$ However, continuity of these efforts is hampered by the lack of resources for programs. Furthermore, young sex workers' role in these efforts is typically confined to that of peer educator. Drawing on Arnstein's seminal model of participation, this is conceptualized as "passive", rather than active, involvement in key decisions to shape programs contributing to their effectiveness. ${ }^{1}$ Globally, there are notable examples of high-risk communities self-mobilizing to gain a more significant role than that of educator, embracing a more activist participation. Thailand has had some success in this; eg, Service Workers in Group (commonly known as SWING), a community of sex workers, successfully mobilized the media and powerful forces to counter stigma, raise awareness, and attract resources. ${ }^{18,19}$

A small-scale exploratory study was supported by Mahidol University's Institute for Population and Social Research (IPSR) in Bangkok and was linked to a national study that took place from 2010 to 2013, namely, Evaluation of the National HIV Prevention Program for Key Affected Populations, Migrant Workers and Prisoners. ${ }^{20}$ Ethics approval was granted by IPSR in August 2012 and by Auckland University of Technology Ethics Committee in November 2012. Fieldwork took place over a 3-month period in 2013 .

The study took place in Bangkok - a major center for the sex industry in Thailand. Sex work in Bangkok is concentrated within the Soi Cowboy, Patpong, and Nana Entertainment Plaza areas. Soi Cowboy is known for its strip clubs and coyote bars, many of which offer sexual services. Sex work is negotiated at these sites but takes place off site. IPSR assisted in the recruitment of participants through SWING, an organization providing education, outreach activities, and other projects aimed at empowering sex workers. Sex worker collectives, such as the SWING, often play a crucial role in accessing this hard-to-reach population. The study was designed to maximize confidentiality and safety for participants while providing them with a comfortable space to talk about participation. ${ }^{21}$ An advertisement was placed at the SWING Bangkok center inviting four to six young women, as well as a small number of community support workers, to participate in the study. A presentation was made at the drop-in center to inform potential participants. A drop-in box, with expression of interest and consent forms, was provided at the center for potential participants. Participants were provided with information in Thai language, and they had 1 week to consider whether they would like to participate. Written informed consent was obtained 1 week after the meeting. Five young women sex workers (aged 20-24 years) and two community support workers were recruited; they were interviewed individually using a semistructured approach. Interviews were structured around three questions: 1) Do you think that young women sex workers' participation in HIV programs is important and, if so, why? 2) What is the extent of current participation in HIV programs? and 3) What are the barriers to and future opportunities for participation? Interviews were conducted in a private room at the drop-in center; they lasted $\sim 90$ minutes and were in Thai language. 
They were digitally audio recorded, transcribed, and then translated into English with the assistance of a translator experienced in conducting research among sex workers. Data were checked with participants on completion of the interviews and analyzed by the primary researcher, a young Southeast Asian woman, using a participation-based thematic analysis drawing on Arnstein's model of community participation. ${ }^{1,22}$ In the following discussion, which draws from the views gathered during the study, pseudonyms are used throughout.

Looking to the future, Internet-based collaborative and prosumer models within a digital society offer new opportunities for participation. ${ }^{23,24}$ In the context of epublic health, ehealth promotion, and ehealth services, collaborative and prosumer models position people as codesigners, leaders, and producers of knowledge and ideas, not as passive consumers of health programs designed by institutions. ${ }^{25}$ Based in part on reflections on the study, this study makes suggestions that look toward new opportunities - and indeed risks - offered by the digital society in a new type of participation.

\section{Discussion}

\section{Young women sex workers as educators and experts}

Young women sex workers in Bangkok, Thailand, are not strangers to HIV programs. Participants described their experiences and views freely. In doing so, they noted the risks associated with participating and made related suggestions as discussed herein. Participants were involved in HIV programs primarily as educators, drawing on personal expertise in the field of sex work to educate others.

What I did was basically peer education, for example giving knowledge about the difference between AIDS and HIV, and how it is infected, and what kind of tests do they require.

[Malee, sex worker]

Others had taken part in outreach activities that involved condom distribution. Through actively participating in these HIV programs, the young women sex workers perceived themselves as experts in those aspects of life related to their trade.

If you separate those teenagers who are sex workers and those who are not, it seems that sex workers may be at risk. But they actually practice safe sex more than the regular teenagers because they all know that they are exposed to risks and what the risks are. [Phara, sex worker]
Expertise is acquired over time, and participants acknowledged that older sex workers could potentially contribute more to education:

[...] the younger ones who have just entered the business may have less knowledge about HIV compared to those older ones. [Amporn, sex worker]

Thus, young women positioned themselves as educators having expertise to share, which is at odds with their place in society where they are positioned as having little status and as educationally deficient.

\section{Young women sex workers participating in decision-making}

Sex workers are a priority group for HIV; yet, the illegal nature of sex work and the resultant violence and intimidation create significant barriers to their participation in HIV programs in the form of stigma, shame, and a desire to hide.

The stigmatization and the attitude of the people in general toward sex worker, that it's a bad thing. [Phara, sex worker]

Maybe it's because most of the people do not approve of me as a prostitute, as a sex worker, mainly because of my occupation. [Amporn, sex worker]

The experience of stigma effectively silenced the participants and was reflected in a desire to remain anonymous, creating a challenge for participation.

If it's small activity like maybe having lunch together and then at the same time talk about sex education or STIs, how to protect ourselves or do it over coffee then it would be more tempting to participate. Because if it's a big campaign where everybody gathers, people see who we are. [Tui, sex worker]

This resonates with the IPSR 2012-2013 study, ${ }^{20}$ which found that many sex workers had not disclosed their occupation to their families for fear of being shunned. Such negative attitudes experienced by sex workers are described as being widely present among the police, the government, the general public, and respective families, and pose a particular challenge, given that participation is associated with community harmony. Phara showed a sophisticated understanding of the wider policy arena and the challenge faced in addressing status.

If the government actually involves them in policy making, if the government launches any regulation that would help them, other people, the public may think that the 
government is trying to encourage prostitution. [Phara, sex worker]

Issues of illegality and stigma relate to all sex workers, but young sex workers are particularly disadvantaged by low status and lack of experience in the sex industry:

Young sex workers are facing different problems like for example they do not know their rights and they have less bargaining power when it comes to negotiating the prices, the pay. If we include the young sex workers it will actually give significant impact and help them. [Kiet, community support worker]

Kiet's words reflect the well-founded fear of the young women's illegal status, which exposes them to violence and exploitation, and the social stigma, which keeps them silent, seeking anonymity. Yet, despite the difficulties, she calls for greater involvement of young women sex workers in decision-making.

Statutory and other formal decision-making roles are less likely to be ignored, although it is important to put mechanisms in place to make sure that they are not tokenistic. This will not be easy given the voicelessness and fear experienced by young women and their concerns for safety and privacy. It will require considerable effort and a genuine desire to provide a space for the voices of young women in such programs. As a result of this, HIV programs would become more accountable to the at-risk population served. As well as ensuring greater user accountability, positioning young women as leaders, by itself, does start to change their place in the society.

\section{Conclusion}

This study draws on the participation experiences and views of young women sex workers and related community support workers in HIV programs. Some had experience of peer education, which they saw as participation, although this was the extent of their involvement in HIV programs. Participants expressed positive views about participating but were especially concerned about the need for safety and anonymity in relation to programs. Current participation theory, research, and practice, including that of the authors, ${ }^{5,26}$ suggest that participation in HIV initiatives needs to position young women sex workers as experts, codecision makers, and leaders, as well as peer educators. There is a need for more formal, statutory opportunities for young women to be meaningfully represented on decision-making bodies and panels.

Looking to the future, and considering the widespread use of smartphones, Internet-based collaborative and prosumer models offer new opportunities for participation. ${ }^{24}$ A "prosumer" model, first coined by Toffler ${ }^{23}$ to reflect the blurring of lines between the consumer and producer, resonates with activist participation or self-mobilization models in that it is about people taking action independently from institutions often alongside their own interests, identities, and networks. ${ }^{1}$ It poses significant challenges to old-style institutions and programs, making way for new-style collaboration, different ways of resourcing and networking, and creative ways for young women to express their identity and influence change. However, given the social environment for such young women, the Internet poses risks as well as opportunities, for instance, from the dangers of public exposure. Further research is needed in this growing area of public health and in relation to the social reality of designing and implementing such participation practice in the context of rapid social and technological change.

Empowerment and codesign methodologies, working in partnership with young women sex workers and HIV programs, provide a valuable mechanism to ensure that research is relevant and likely to have a positive outcome for their health. HIV programs should assist in developing new participation concepts and tools, building on innovative trends such as the collaborative commons and prosumerism, acknowledging and harnessing the changing context provided by the digital society.

Yet, enhanced participation by itself is not enough; it needs to contribute to a wide range of strategies that address illegality, low status, and stigmatization by the wider society. Without addressing the wider harmful environment and norms for young women sex workers, participation, while beneficial within the space of programs, is unlikely to contribute to reduced rates of HIV in this vulnerable population. Creating a safe space for such groups to have a say is no easy task and highlights the need for change in the social environment that delivers the conditions for marginalization. ${ }^{26,27}$

\section{Acknowledgments}

This study is based in part on a Master of Public Health research project by Kristel Modderman and it was supported by Mahidol University's Institute for Population and Social Research (IPSR) in Bangkok. It is linked to a national study that took place from 2010 to 2013: Evaluation of the National HIV Prevention Program for Key Affected Populations, Migrant Workers and Prisoners.

\section{Author contributions}

$\mathrm{CC}$ led the writing and analysis for this study. KM designed and undertook the literature review, fieldwork, and data 
analysis for this study. SN contributed to the writing and analysis for this study. All authors contributed toward data analysis, drafting and critically revising the paper and agree to be accountable for all aspects of the work.

\section{Disclosure}

The authors report no conflicts of interest in this work.

\section{References}

1. Arnstein SR. A ladder of citizen participation. J Am Inst Plann. 1969; 35(4):216-224.

2. Barnes M. Users as citizens: collective action and the local governance of welfare. Soc Pol Admin. 1999;33(1):73-90.

3. Rifkin SB, Muller F, Bichmann W. Primary health care: on measuring participation. Soc Sci Med. 1988;26(9):931-940.

4. Frankish CJ, Kwan B, Ratner PA, Higgins JW, Larsen C. Challenges of citizen participation in regional health authorities. Soc Sci Med. 2002;54(10):1471-1480

5. Conn C, Modderman K, Nayar S. At the limits of participation: 'Most at risk' populations and HIV programs. Dev Bul. 2013;75. Available from: https://crawford.anu.edu.au/rmap/devnet/devnet/db-75.pdf. Accessed February 17, 2017.

6. Cornish F, Campbell C, Shukla A, Banerji R. From brothel to boardroom: prospects for community leadership of HIV interventions in the context of global funding practices. Health Place. 2012;18(3):468-474.

7. Conn C, Waite L. Young women's voices and HIV/AIDS in Uganda. J Health Organ Manag. 2010;24(5):483-490.

8. Kerrigan D, Wirtz A, Baral S, et al. The Global HIV Epidemics among Sex Workers. Washington, DC: World Bank Publications; 2013.

9. Decker MR, McCauley HL, Phuengsamran D, Janyam S, Silverman JG. Sex trafficking, sexual risk, sexually transmitted infection and reproductive health among a national sample of FSWs in Thailand. J Epidemiol Community Health. 2011;65(4):334-339.

10. Decker MR, McCauley HL, Phuengsamran D, Janyam S, Seage GR 3rd, Silverman JG. Violence victimisation, sexual risk and sexually transmitted infection symptoms among female sex workers in Thailand. Sex Transm Infect. 2010;86(3):236-240.

11. Nemoto T, Iwamoto M, Sakata M, Perngparn U, Areesantichai C. Social and cultural contexts of HIV risk behaviors among Thai female sex workers in Bangkok, Thailand. AIDS Care. 2013;25(5):613-618.

12. WHO. Prevention and Treatment of HIV and Other Sexually Transmitted Infections for Sex Workers in Low- and Middle-income Countries Recommendations for a Public Health Approach. Geneva: WHO; 2013. Quote from page 37.
13. UNAIDS. UNAIDS Guidance Note on HIV and Sex Work. Geneva: UNAIDS; 2009.

14. Liamputtong P, Haritavorn N, Kiatying-Angsulee N. HIV and AIDS, stigma and AIDS support groups: perspectives from women living with HIV and AIDS in central Thailand. Soc Sci Med. 2009;69(6): 862-868.

15. Van Griensven GJ, Limanonda B, Ngaokeow S, Ayuthaya SI, Poshyachinda V. Evaluation of a targeted HIV prevention programme among female commercial sex workers in the south of Thailand. Sex Transm Infect. 1998;74(1):54-58.

16. Visrutaratna S, Lindan CP, Sirhorachai A, Mandel JS. 'Superstar' and 'model brothel': developing and evaluating a condom promotion program for sex establishments in Chiang Mai, Thailand. AIDS. 1995; 9(suppl (1)):S69-S75.

17. Government of Thailand \& UNDP. Southern Thailand Empowerment \& Participation (STEP) Project 2010-2012. Thailand: Government of Thailand \& UNDP; 2010.

18. Rasanathan K, Posayanonda T, Birmingham M, Tangcharoensathien V. Innovation and participation for healthy public policy: the first National Health Assembly in Thailand. Health Expect. 2012;15(1):87-96.

19. Service Workers in Group Foundation (SWING) [webpage on the Internet]. Regional updates: Asia and the Pacific. Available from: http:// www.nswp.org/members/asia-and-the-pacific/swing-serviceworkersgroup. Accessed February 17, 2017.

20. Institute for Population and Social Research Mahidol University. Evaluation of the National HIV Prevention Program for Key Affected Populations, Migrant Workers and Prisoners. Bangkok, Thailand: Institute for Population and Social Research Mahidol University; 2013.

21. Pyett PM. Validation of qualitative research in the "real world". Qual Health Res. 2003;13(8):1170-1179.

22. Braun V, Clarke V. Using thematic analysis in psychology. Qual Res Psych. 2006;3(2):77-101.

23. Toffler A. The Third Wave. New York: Bantam Books; 1981.

24. World Bank. World Development Report 2016: Digital Dividends. Washington, DC: World Bank Publications; 2016.

25. Eysenbach G. What is e-health? J Med Internet Res. 2001;3(2):e20

26. Conn C. Young African women must have empowering and receptive social environments for HIV prevention. AIDS Care. 2012;25(3): 273-280.

27. Campbell C, Cornish F. Towards a 'fourth generation' of approaches to HIV/AIDS management: creating contexts for effective community mobilisation. AIDS Care. 2010;22(suppl 2):1569-1579.
International Journal of Women's Health

\section{Publish your work in this journal}

The International Journal of Women's Health is an international, peerreviewed open-access journal publishing original research, reports, editorials, reviews and commentaries on all aspects of women's healthcare including gynecology, obstetrics, and breast cancer. The manuscript management system is completely online and includes

\section{Dovepress}

a very quick and fair peer-review system, which is all easy to use. Visit http://www.dovepress.com/testimonials.php to read real quotes from published authors. 